DOI https://doi.org/10.15589/znp2020.1(479).7

УДК 681.516 .75

\title{
FUZZY DYNAMIC CORRECTOR FOR OBJECTS WITH PARAMETRIC INSTABILITY
}

\section{НЕЧІТКИЙ ДИНАМІЧНИЙ КОРЕКТОР ДЛЯ ОБ'СКТІВ ІЗ ПАРАМЕТРИЧНОЮ НЕСТАЦІОНАРНІСТЮ}

\author{
Taras G. Bahan \\ mtbagan@ukr.net \\ ORCID: 0000-0002-0146-577X \\ Mykhajlo Kuzin \\ workavgmike@gmail.com \\ ORCID: 0000-0002-0813-8712
}

\author{
Т. Г. Баган, \\ канд. техн. наук, доцент \\ М. Ю. Кузін, \\ магістрант
}

National Technical University of Ukraine “Igor Sikorsky Kyiv Polytechnic Institute”, Kyiv

Національний технічний університет Украӥни «Київський політехнічний інститут імені Ігоря Сікорського», м. Київ

\begin{abstract}
Purpose. Parametric non-stationarity is quite common in traditional energy facilities that use the combustion of different types of organic fuel. However, even defining the boundaries of such instability for working equipment, in many cases, becomes almost impossible. At the same time, the main task remains to ensure a stable mode of operation and preferably in an optimal mode in terms of energy efficiency. The purpose of the study is to analyze the principle of operation of a fuzzy controller, as well as to use fuzzy logic in the construction of non-standard regulators to control non-stationary technological objects.
\end{abstract}

Method. The algorithm for fuzzy correction device synthesis for the controller consists of the following steps: identification of the control object, customization of the traditional controller, compilation of a rule base based on the research results. Two separate databases were built for allow simultaneous and independent change of two controller parameters. The error signal and the derivative of the error signal are selected for the input signals of the fuzzy controllers corresponding to them.

Results. The fuzzy controller is more likely to overcome perturbations in the control system when the oscillation capacity of the control object increases. This feature makes the control system several times faster and reduces the maximum dynamic emission. In particularly critical conditions, a fixed adjustment of the PI controller can cause the control system loses stability. The results obtained from modeling of the work of the dynamic corrector prove that the dynamic corrector of the PI controller based on fuzzy logic provides better regulation, shorter adjustment time, faster overcoming perturbations, and reduces the maximum dynamic error.

Scientific novelty. The proposed technique for adjusting the fuzzy dynamic corrector reduces the oscillatory capacity of the system and allows it to be stable in all critical states of the object.

Practical importance. The introduction of the dynamic corrector improves, and in some cases dramatically changes the transition process. The application of fuzzy logic leads to an improvement in the quality of regulation in conditions of parametric non-stationarity of the object.

Key words: corrector; identification; fuzzy logic; control system.

Анотація. Мета. Параметрична нестаціонарність досить часто зустрічається і в об'єктах традиційної енергетики, що використовують спалювання різних видів органічного палива. Однак навіть визначення меж такої нестабільності для працюючого обладнання часто стає майже нездійсненним. При цьому основним завданням залишається забезпечення стабільного режиму роботи й бажано в оптимальному 3 точки зору енергоефективності режимі. Метою дослідження $є$ аналіз принципу роботи нечіткого регулятора, а також використання нечіткої логіки під час побудови нестандартних регуляторів для керування нестаціонарними технологічними об'єктами.

Методика. Алгоритм синтезу нечіткого коригуючого пристрою для регулятора складається 3 таких етапів, як ідентифікація об'єкта керування, налаштування традиційного регулятора, складання бази правил, які базуються на результатах досліджень. Для отримання можливості одночасної та незалежної зміни двох параметрів регулятора побудовано дві окремі бази даних. За вхідні сигнали відповідних їм нечітких контролерів вибрані сигнал помилки й похідна від сигналу помилки. 
Результати. Нечіткий регулятор швидше долає збурення в системі керування тоді, коли коливальна здатність об'єкта керування зростає. Така властивість робить систему керування в декілька разів швидшою, а також зменшує максимальний динамічний викид. В особливо критичних умовах фіксована настройка ПІ-регулятора може навість привести до того, що система керування втрачає стійкість. Отримані результати моделювання роботи динамічного коректора доводять, що динамічний коректор ПІ-регулятора на базі нечіткої логіки забезпечує більш якісне регулювання, менший час регулювання, швидше долає збурення та зменшує максимальну динамічну помилку.

Наукова новизна. Запропонована методика налаштування нечіткого динамічного коректора передбачає зменшення коливальної здатності системи та дає змогу утримувати їі стійкою за всіх критичних станів об'єкта. Практична значимість. Введення динамічного коректора покращує, а іноді навіть кардинально змінює перехідний процес. Застосування нечіткої логіки приводить до підвищення якості регулювання в умовах параметричної нестаціонарності об'єкта.

Ключові слова: коректор; ідентифікація; нечітка логіка; система керування.

\section{ПОСТАНОВКА ЗАДАЧІ}

Параметрична нестаціонарність досить часто зустрічається і в об’єктах традиційної енергетики, що використовують спалювання різних видів органічного палива. Проте навіть визначення меж такої нестаціонарності для працюючого обладнання часто стає майже нездійсненним. Насамперед це викликано обмеженістю проведення на такому обладнанні експериментальних досліджень. До того ж часто має місце неповнота математичного опису, яка зумовлена лінеаризацією та апроксимацією характеристик його елементів. Водночас одним з головних завдань залишається забезпечення стабільного режиму роботи й бажано в оптимальному з точки зору енергоефективності режимі. Всі ці чинники спричиняють суттєві розбіжності між результатами моделювання поведінки синтезованих автоматичних систем регулювання (ACP) та реальними експериментальними даними, отриманими під час пуско-наладки та експлуатації.

Відмінність АСР зі звичайним ПІД-регулятором від АСР з контролером, заснованим на нечіткій логіці, полягає в тому, що в останній коефіцієнти підсилення в пропорційному та інтегруючому ланцюгах регулятора не є статичними, тобто залежать від стану системи в поточний момент часу [1]. Це дає змогу якісно змінити процес керування, врахувати параметри сигналів у системі (швидкість зміни сигналу, прискорення), а також зробити процес керування більш адаптивним. На рис. 1 наведено загальну схему замкненої системи з коректором ПІД-регулятора на основі нечіткої логіки.

\section{МЕТА ДОСЛІДЖЕННЯ}

Метою дослідження $є$ аналіз принципу роботи нечіткого регулятора, а також використання нечіткої логіки під час побудови нестандартних регуляторів для керування нестаціонарними технологічними об'єктами.

Для досягнення поставленої мети необхідно вирішити такі завдання:

- дослідження параметрично нестаціонарного об’єкта керування та виявлення причин виникнення параметричної нестабільності;

- проведення синтезу лінійного ПІ-регулятора для параметрично нестаціонарного об'єкта;

- синтезування динамічного коректора параметрів ПІ-регулятора на базі нечіткої логіки;

- дослідження різниці як керування на базі ПI-регулятора та регулятора 3 використанням динамічного коректора на базі нечіткої логіки.

Об'єктом дослідження є теплиця, для якої існує необхідність керування мікрокліматом. Підтримання необхідного мікроклімату з додержанням необхідних параметрів досягається шляхом використання вентиляційних систем регулювання заданих значень температур та вологості.

Для якісного та кількісного регулювання параметрами мікроклімату теплиці необхідно постійно підтримувати встановлені значення температури



Рис. 1. Структурна схема нечіткого ПІД-регулятора 


\section{АВТОМАТИЗАЦІЯ ТА КОМП'ЮТЕРНО-ІНТЕГРОВАНІ ТЕХНОЛОГІЇ № 1 — 2020}

та вологості цілорічно. Параметрична нестаціонарність теплиці як об'єкта керування викликана зміною елементів теплового балансу тепла та вологи всередині теплиці, яка має вентиляційні системи керування. Найкращі результати роботи системи вирощування врожаю досягаються дослідженням i врахуванням усіх можливих впливів та факторів на роботу об'єкта. Процеси підтримання температури та вологи виглядають як аперіодичні з урахуванням теплового балансу на базі першого закону термодинаміки [2].

\section{ОСНОВНИЙ МАТЕРІАЛ}

Розглянемо об'єкт керування температурою у вигляді двох ланок, які акумулюють енергію, де першою є ланка води, що гріє (використання установки водяного калорифера), другою - ланка повітря теплиці, що підігрівається. Графічно він представлений на рис. 2.

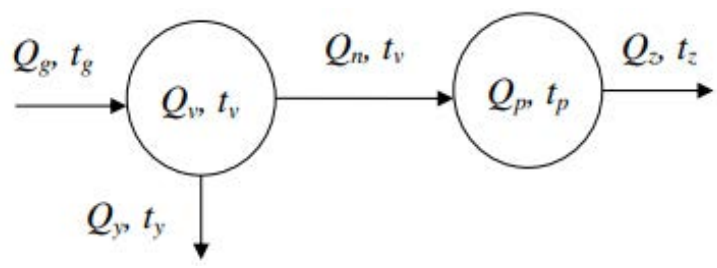

Рис. 2. Схема потоків тепла в теплиці

Примітка: $t_{p}$ - температура повітря; $t_{v}$ - температура води в трубах; $t_{g}$ - температура подачі теплоносія; $\mathrm{t}$ - зворотна температура теплоносія; $t_{z}$ - температура зовнішнього середовища; $Q_{p}-$ тепло, яке знаходиться в повітрі; $Q_{\text {v }}$-тепло, яке знаходиться у вод $i$; $Q_{\text {- }}-$ тепло, введене з водою; $Q_{y}-$ тепло, виведене з водою; $Q_{n}-$ тепло, шьо перейшло до повітря; $Q_{z}$ - тепло, витрачене на навколинній простір

У статичному режимі величини тепла, що знаходиться у воді $\left(\mathrm{Q}_{v}\right)$, і тепла, що знаходиться у повітрі теплиці $\left(Q_{p}\right)$, залишаються незмінними, тому можемо записати два рівняння теплових балансів згідно з першим законом термодинаміки для води й повітря:

$$
\begin{gathered}
Q_{g}-Q_{y}-Q_{n}=0, \\
Q_{n}-Q_{z}=0 .
\end{gathered}
$$

Також у теплиці відбувається обмін вологою. На їі кількість впливають температура повітря, евапотранспірація рослин і сонячне випромінювання, поглинене теплицею.

Евапотранспірація - це кількість вологи, що переходить в атмосферу у вигляді пари в результаті десукції, подальшої транспірації та фізичного випаровування.

Враховуючи схеми теплових балансів для цього об'єкта, можемо записати зміни стану температури і вологості в диференційній формі [2]:

$$
\begin{gathered}
\frac{d T_{в H}(t)}{d t}=\frac{1}{p C_{B} V_{m}}\left[Q_{n}(t)+S_{n}(t)-\lambda Q_{m}(t)\right]- \\
-\left(\frac{v_{B}(t)}{V_{m}}+\frac{k_{m}}{p C_{B} V_{m}}\right)\left[T_{\theta H}(t)+T_{\text {зн }}(t)\right] \\
\frac{d \varphi_{B H}(t)}{d t}=\frac{Q_{m}}{V_{m}}+S_{n}(t)-\frac{v_{B}(t)}{V_{m}}\left[\varphi_{\theta H}(t)-\varphi_{3 н}(t)\right] \\
S_{n}(t)=\lambda * \varphi_{\text {вн }} * E(t),
\end{gathered}
$$

де $\mathrm{T}_{в н}, T_{\text {зн }}$ - температура повітря всередині та зовні теплиці; $\varphi_{\text {вн }}, \varphi_{\text {зн }}-$ відносна вологість повітря всередині та зовні теплиці; $\mathrm{k}_{T}$ - коефіцієнт передачі матеріалу огороджування теплиці; $\mathrm{V}_{\mathrm{m}}$ - повний геометричний об'єм теплиці; $C_{B}-$ питома теплоємність повітря; $Q_{n}$ - потужність обігрівача теплиці; $\mathrm{Q}_{\mathrm{m}}$ - продуктивність системи адсорбції повітря; $S_{n}-$ сонячне випромінювання поглинене теплицею; $\lambda$ - питома теплота процесу абсорбції; $E$ - евапотранспірація рослин у функції поглиненого сонячного випромінювання та вологості повітря в теплиці; $v_{B}$ - повітрообмін, забезпечуваний системою вентиляції.

Параметрична нестаціонарність викликана різними значеннями показника $E$ (евапотранспірація), оскільки в теплиці змінюються рослинність та тип рослин, що має безпосередній вплив на процеси теплообміну всередині теплиці. Оскільки більшість параметрів роботи вентиляційних установок нам відома, необхідно емпіричним шляхом визначити зміну евапотранспірації рослин у самій теплиці.

Використовуючи напрацювання [3] та технічні характеристики вентиляційного обладнання, маємо такі показники: $\mathrm{V}_{\mathrm{m}}=16000 \mathrm{~m}^{3}, C_{B}=1,005$ кДж* кг$1 * \mathrm{~K}, \mathrm{k}_{T}=29,81 \mathrm{BT} /{ }^{\circ} \mathrm{C}, \mathrm{Q}_{n}=211,48 \mathrm{\kappa BT}, Q_{m}=200 \kappa \mathrm{\kappa T}$, $\lambda=4,65 \kappa$ кВ, $v_{B}=3,7 \mathrm{~m}^{3} / \mathrm{c}$.

Таким чином, можемо вивести функції передачі об'єкта керування в контурі регулювання температури для таких трьох випадків:

- об'єкт 3 мінімальною рослинністю та евапотраспірацією:

$$
W_{O B} 1=\frac{5.05}{250 s+1} e^{-s 100}
$$

- об'єкт з усередненою рослинністю в перехідний період:

$$
W_{O B} 2=\frac{1.94}{600 s+1} e^{-s 100}
$$

- об'єкт 3 максимальною рослинністю та евапотраспірацією:

$$
W_{O B} 3=\frac{10.21}{80 s+1} e^{-s 100} .
$$

На рис. 3 показані розгінні характеристики цих об'єктів керування. 


\section{Синтез нечіткого динамічного коректора}

Як знання потрібно мати уявлення про величину певних параметрів під час роботи системи. Ці параметри є ні чим іншим, як вхідними та вихідними величинами розроблюваного нечіткого контролера. Оскільки попередньо була вибрана адаптивна система керування з нечітким коригуючим пристроєм (рис. 1), то вихідними параметрами $є$ налаштування класичного ПІ-регулятора, а саме $\mathrm{K}_{\mathrm{p}}$ та $T_{\mathrm{i}}$. Вхідними параметрами можуть слугувати різні величини, зокрема сигнал помилки, похідна від сигналу помилки, інтеграл помилки, швидкість зміни інтегралу помилки. В цьому разі як вхідні параметри нечіткого контролера вибрані сигнал помилки $е$ та похідна від сигналу помилки $d e / \mathrm{dt}$.

Згідно з проведеною ідентифікацією діапазон зміни параметрів моделі визначається так: $K_{\text {об }} \in[1.94$; $10.21]$ і $\mathrm{T}_{\text {об }} \in[80 ; 600]$. Діапазон змін вхідних параметрів нечіткого динамічного коректора зведено в табл. 1.

За результатами попередніх дослідів [4], пробних моделювань та підстроювання кінцевих моделей нечіткого контролера встановлено діапазон для вхідної лінгвістичної змінної «сигнал помилки» (рис. 4) таким: $[-0,006 ; 0,35]$. Для вхідної лінгвістичної змінної «похідна від сигналу помилки» (рис. 5) діапазон такий: $\left[-2.2 * 10^{-5} ; 0.28\right]$. Діапазон для вихідної лінгвістичної змінної «коефіцієнт $\mathrm{K}_{\mathrm{p}}$ » встановлено таким:
$[0,03 ; 0,9]$. Для вихідної лінгвістичної змінної «коефіцієнт Т i» діапазон такий: [430; 2110].

Розбиття змінних визначалося емпіричним шляхом. Кінцевий результат показано на рис. 6 (для коефіцієнта $\mathrm{K}_{\mathrm{p}}$ ) та рис. 7 (для коефіцієнта $\mathrm{T}_{\mathrm{i}}$ ).

Розбиття змінних на терми відбувалося задля досягнення таких результатів:

1) забезпечення плавності переходу між різними термами за рахунок часткового накладання;

2) виділення окремих термів для характеристики розміру сигналу помилки як «основного» $(\mathrm{mfl})$, «близького до нуля» (mf2), «в зоні перерегулювання» (mf3), а сигналу похідної від помилки як «швидко зростаючого» $(\mathrm{mfl})$, «повільно зростаючого» $(\mathrm{mf} 2)$ та «спадаючого» (mf3).

Оскільки досліджуваному об'єкту керування властива параметрична нестаціонарність, то необхідно розробити таку логіку керування, щоб вона задовольняла всі його стани. Для цього пропонується взяти до уваги такі твердження [5]:

1) на самому початку перехідного процесу необхідно максимально збільшити коефіцієнт регулятоpa $\mathrm{K}_{P}$ та максимально зменшити коефіцієнт регулятора $T_{\text {, }}$ що дасть змогу швидко подолати збурення;

2) на етапі, що йде після першого закиду, необ-

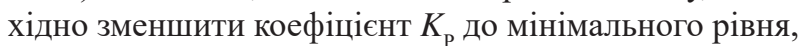
а коефіцієнт $\mathrm{T}_{\mathrm{i}}$ - збільшити;

Таблиця 1. Діапазон вхідних параметрів нечіткого динамічного коректора

\begin{tabular}{|c|c|c|c|c|c|c|}
\hline $\mathrm{K}$ & $\mathrm{T}$ & $\tau$ & e_min & e $\_\max$ & de/dt_min & de/dt_max \\
\hline 5,05 & 250 & 100 & $-0,006145$ & 0,23 & $-2,39^{*} 10^{-5}$ & 0,02091 \\
\hline 1,94 & 600 & 100 & $-0,00589$ & 0,14 & $-2,17 * 10^{-5}$ & 0,01856 \\
\hline 10,21 & 80 & 100 & $-0,00785$ & 0,31 & $-2,68^{*} 10^{-5}$ & 0,03045 \\
\hline
\end{tabular}

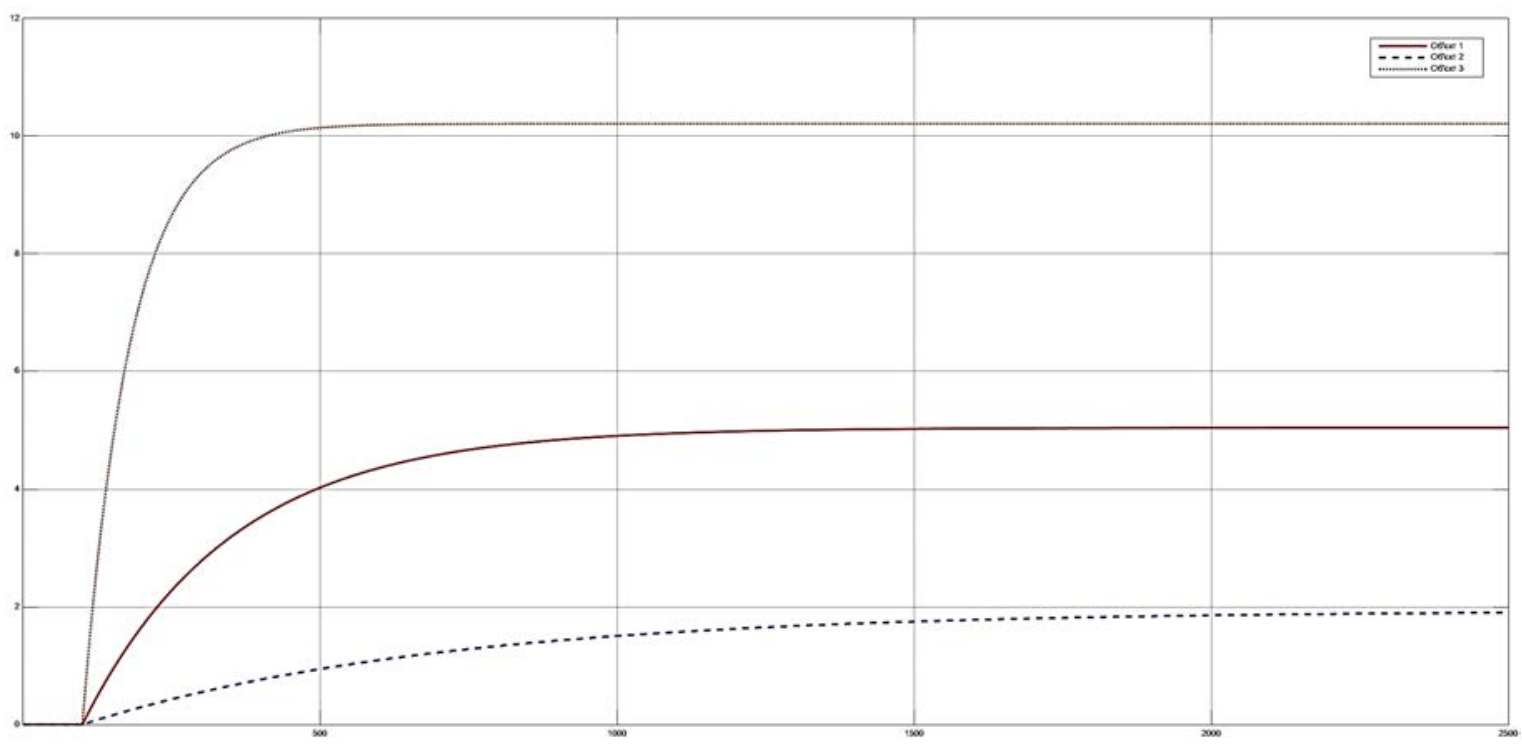

Рис. 3. Розгінні характеристики для трьох моделей контуру регулювання температур 


\section{АВТОМАТИЗАЦІЯ ТА КОМП'ЮТЕРНО-ІНТЕГРОВАНІ ТЕХНОЛОГІЇ № 1 г 2020}

3) коли сигнал помилки й похідна від сигналу помилки близькі до нуля (процес близький до встановлення), слід встановити коефіцієнти $\mathrm{K}_{p}$ та $\mathrm{T}_{\text {; на }}$ нормальному рівні для більшості станів об'єкта.

На основі описаних тверджень була укладена база правил для параметрів ПІ-регулятора (табл. 2, 3).

Для того щоби була можливість одночасно й незалежно змінювати два параметри ПІ-регулятора, побудовано дві окремі бази даних. Вхідні сигнали відповідних їм нечітких контролерів однакові, а саме сигнал помилки $e$ і похідна сигналу помилки $d e / d t$. Вихідним сигналом одного нечіткого контролера $\epsilon$ параметр налаштування $\mathrm{K}_{P}$, а іншого - Т. Побудована модель засобами Matlab показана на рис. 8.

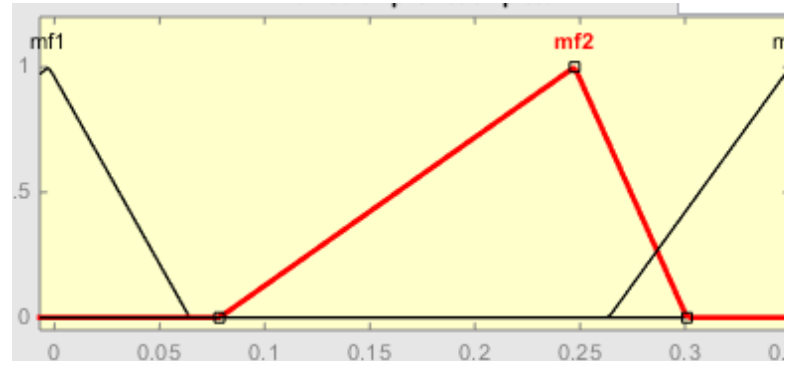

Рис. 4. Терми вхідної лінгвістичної змінної «сигнал помилки»

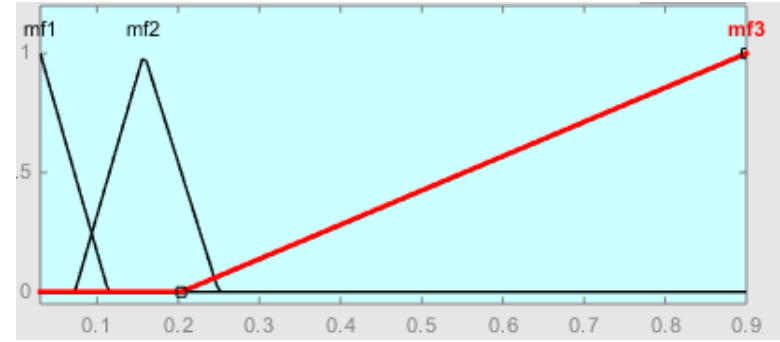

Рис. 6. Терми вихідної лінгвістичної змінної «коефіцієнт $\mathrm{K}_{\mathrm{p}}$ »
Результат роботи коректора залежно від параметрів об'єкта показано на рис. 9-11.

Порівняльний аналіз показників якості перехідних процесів занесено в табл. 4.

В результаті порівняльного аналізу можна стверджувати, що одноконтурна система керування 3 нечітким динамічним коректором працює краще, ніж класична система керування 3 ПІ-регуляторами в умовах параметричної нестаціонарності. Це можна стверджувати на підставі того, що нечіткий регулятор швидше долає збурення в системі керування тоді, коли коливальна здатність об'єкта керування зростає. Така властивість робить систему керування в декілька разів швидшою, а також зменшує

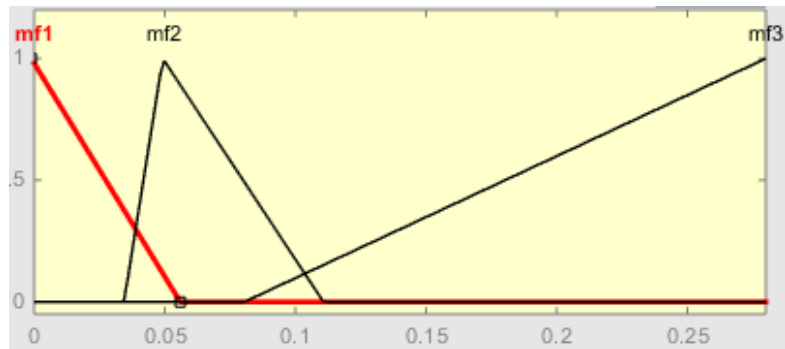

Рис. 5. Терми вхідної лінгвістичної змінної «похідна від сигналу помилки»

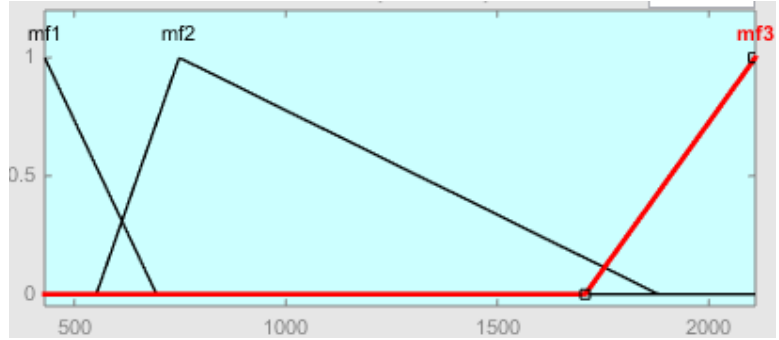

Рис. 7. Терми вихідної лінгвістичної змінної «коефіцієнт $\mathrm{T}_{\mathrm{i}}$ »

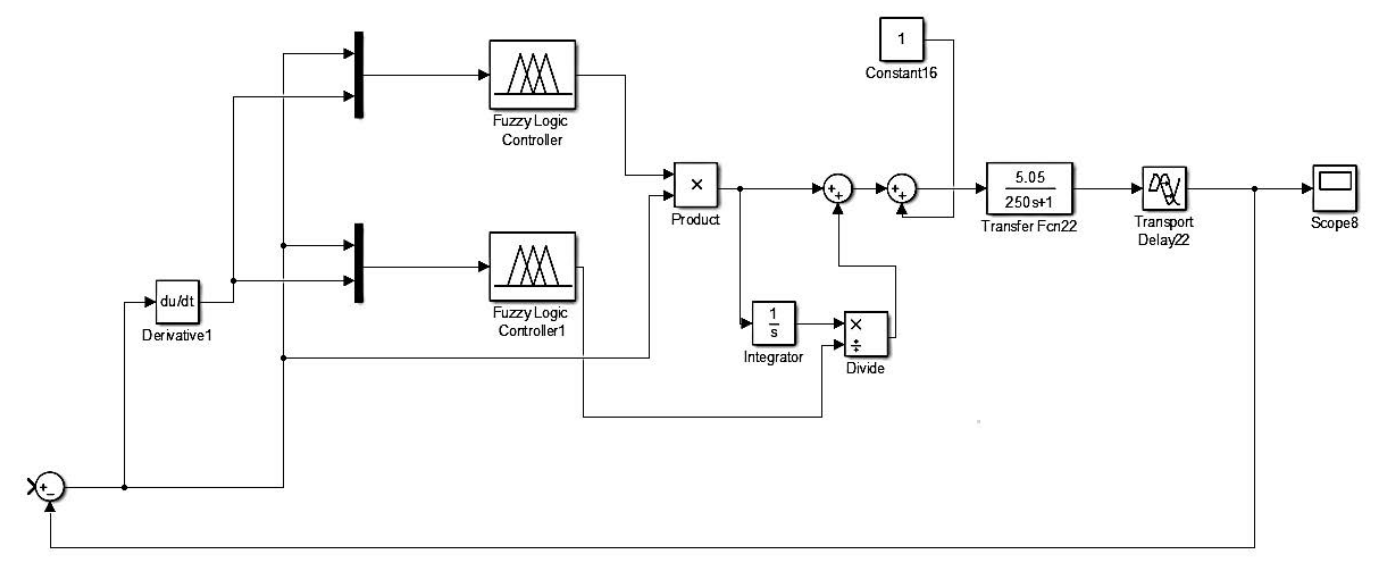

Рис. 8. Модель замкненої системи керування з нечітким коректором ПІ-регулятора 
максимальний динамічний викид. В особливо критичних умовах фіксована настройка ПІ-регулятора може привести до того, що система керування навіть втратить стійкість.

Запропонована методика налаштування нечіткого динамічного коректора передбачає зменшення коефіцієнта підсилення та збільшення сталої часу ПІзакону в ситуаціях, коли сигнал помилки та похідна від сигналу помилки близькі до нуля (по каналу «збурення - вихід»). Це зменшує коливальну здатність системи та дає змогу утримувати ії стійкою за всіх критичних станів об'єкта.

\section{ВИСНОВКИ}

На основі проведеного дослідження можна зробити такі висновки.

1) Виконано моделювання об'єкта керування для умов параметричної нестаціонарності. На базі дослідження трьох станів об'єкта визначені діапазони вхідних та вихідних сигналів нечіткого коректора.

2) 3 огляду на дані, отримані в ході моделювання динаміки об'єкта керування та його параметричної нестаціонарності, розроблена база правил для блоку логічного виводу нечіткого коректора.

3) Виконано порівняльний аналіз, який показав, що АCP $з$ нечітким коректором ПІ-регулятора краще пристосована до роботи з цим об'єктом. Про це свідчать прямі показники якості, наведені в таблиці 5. За збільшеної динаміки об'єкта керування нечіткий регулятор швидше долає збурення, прямі показники якості істотно кращі, ніж у системі з класичним ПІ-регулятором. Аналогічно за зменшення динаміки об'єкта нечіткий коректор значно краще та швидше регулює процес за каналом «збурення - вихід».

Таблиця 4. Показники якості роботи систем для різних станів ОК

\begin{tabular}{|c|c|c|c|c|c|c|}
\hline \multirow{2}{*}{ Показник якості } & \multicolumn{2}{|c|}{ Номінальний } & \multicolumn{2}{|c|}{ Зменшена динаміка } & \multicolumn{2}{|c|}{ Збільшена динаміка } \\
\hline & III & Fuzzy & III & Fuzzy & III & Fuzzy \\
\hline Статична похибка & 0 & 0 & 0 & 0 & Система нестійка & 0 \\
\hline $\begin{array}{c}\text { Максимальний } \\
\text { динамічний викид }\end{array}$ & 2,21 & 2,32 & 0,89 & 0,6 & Система нестійка & 9,1 \\
\hline Ступінь затухання & 1 & 1 & 0,89 & 1 & Система нестійка & 1 \\
\hline Час регулювання & 1800 & 2400 & 4200 & 1890 & Система нестійка & 1150 \\
\hline Перерегулювання & - & - & $11 \%$ & - & Система нестійка & - \\
\hline
\end{tabular}

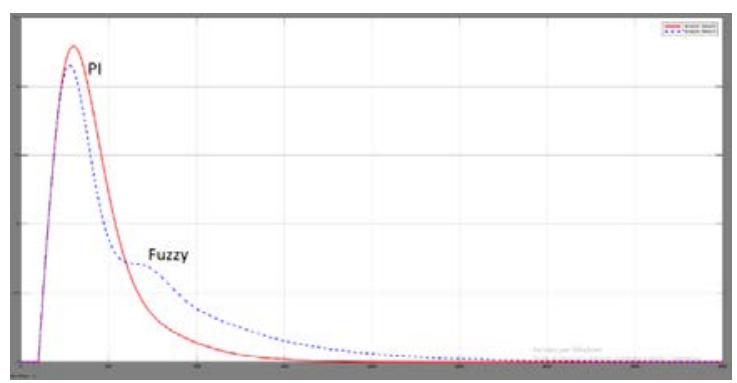

Рис. 9. Перехідний процес за номінальних параметрів об'єкта

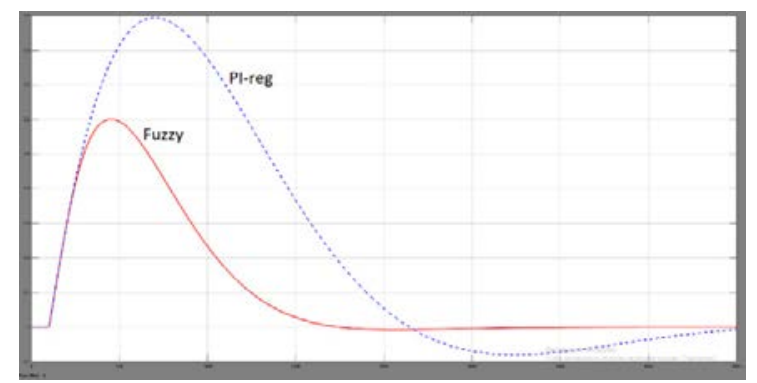

Рис. 10. Перехідний процес за зменшеної динаміки об'єкта

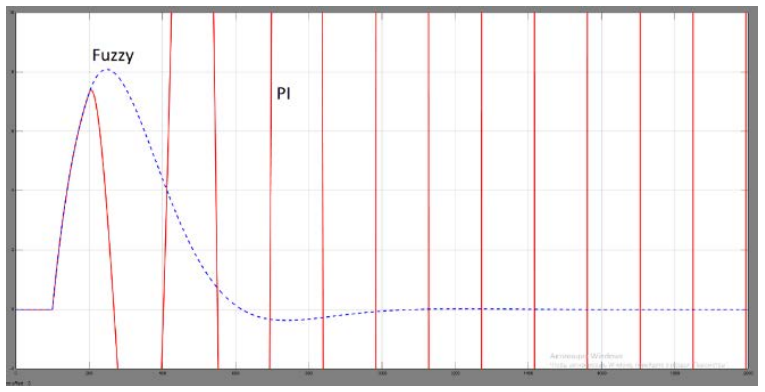

Рис. 11. Перехідний процес за збільшеної динаміки об'єкта 


\section{АВТОМАТИЗАЦІЯ ТА КОМП'ЮТЕРНО-ІНТЕГРОВАНІ ТЕХНОЛОГІЇ № 1 - 2020}

\section{REFERENCES}

[1] Boshliakov, A.A., Rubtsov, V.I. (2013). Proektirovanie nechetkoho reguliatora sledijaschej sistemy [Designing a fuzzy controller for a tracking system]. Engineering Journal: Science and Innovation, № 8 (20), pp. 28-39.

[2] Takakura, T., Son, J.E. (2004). Simulation of biological and environmental processes. Kyushu University Press.

[3] Tokmanov, N.M., Grudinin, V.S. (2008). Matematicheskaya model sistemy upravlenija microclimatom angarnyh teplits [Mathematical model of a microclimate control system for hangar greenhouses]. Nauchnoisledovatelskiy institut ovoschevodstva zachychennogo grunta (NIIOZG), № 3, pp. 28-32.

[4] Bahan, T.H., Kuzin, M.Y. (2019). Fuzzy-logic controler dlia keruvannia tehnologichnymy objectamy [Fuzzy-logic controller for technological objects management]. KPI Science News, № 2, pp. 7-14.

[5] Shtifzon, O., Novikov, P., Bahan, T. (2018). Development of the adaptive fuzzy-logic device for control system in conditions of parametric non-stationary plant. Eastern-European Journal of Enterprise Technologies, T.1, № 2 (91), pp. 30-37.

\section{СПИСОК ВИКОРИСТАНОЇ ЛІТЕРАТУРИ}

[1] Бошляков, А.А., Рубцов, В.И. (2013). Проектирование нечеткого регулятора следящей системы. Инженерный журнал: наука и инновации. № 8 (20). С. 28-39.

[2] Takakura, T., Son, J.E. (2004). Simulation of biological and environmental processes. Kyushu University Press.

[3] Токманов, Н.М., Грудинин, В.С. (2008). Математическая модель системы управления микроклиматом ангарных теплиц. Научно-исследовательский институт овощеводства защищенного грунта (НИИОЗГ). № 3. С. 28 -32.

[4] Баган, Т.Г., Кузін, М.Ю. (2019). Fuzzy-logic контролер для керування технологічними об'єктами. Наукові вісті НТУУ «KПI». № 2. C. 7-14.

[5] Shtifzon, O., Novikov, P., Bahan, T. (2018). Development of the adaptive fuzzy-logic device for control system in conditions of parametric non-stationary plant. Eastern-European Journal of Enterprise Technologies. T.1. № 2 (91). P. 30-37. 